\title{
COMPARATIVE ALLELOPATHIC ACTIVITY OF RHAZYA STRICTA, PINUS ROXBURGHII, CARICA PAPAYA AND LANTANA CAMARA AGAINST NOXIOUS WEEDS
}

ANWAR, T. ${ }^{1 *}$ - ILYAS, N. ${ }^{1}$ - QURESHI, R. ${ }^{1}$ - QURESHI, H. ${ }^{1,2}-$ GILANI, N. ${ }^{3}-$ KHAN, S $^{4}$. KHAN, S.

A. ${ }^{5}-$ FATIMAH, H. ${ }^{6}-$ WASEEM, M. ${ }^{6}-$ MAHMOOD, R. T. ${ }^{7}-$ MAQSOOD, M. ${ }^{1}$

${ }^{l}$ Department of Botany, Pir Mehr Ali Shah Arid Agriculture University, Murree Road, Shamsabad, Rawalpindi-46300, Punjab, Pakistan

${ }^{2}$ Department of Botany, Government Post Graduate College (Women) Sub-Campus, University of Gujrat, Satellite Town, Rawalpindi-46300, Punjab, Pakistan

${ }^{3}$ Department of Zoology, Pir Mehr Ali Shah Arid Agriculture University, Murree Road, Shamsabad, Rawalpindi-46300, Punjab, Pakistan
${ }^{4}$ Department of Environmental Science, Gomal University, Dera Ismail Khan-29050, Khyber Pakhtunkhwa, Pakistan

${ }^{5}$ Department of Earth and Environmental Science, Bahria University, Islamabad Campus, Shangrilla Road, Sector E-8, Islamabad-44000, Pakistan

${ }^{6}$ Department of Biology, Allama Iqbal Open University, H-8, Islamabad-44000, Pakistan

${ }^{7}$ Department of Biotechnology, Mirpur University of Science and Technology, Mirpur-10250, Azad Jammu \& Kashmir, Pakistan

*Corresponding author

e-mail: drtauseefanwar@hotmail.com; phone: +92-33-3686-0562

(Received 27 $7^{\text {th }}$ Feb 2019; accepted 10 $0^{\text {th }}$ Apr 2019)

\begin{abstract}
Yield maximization' is the last word of modern agriculture for food security of everincreasing population of the world. Maximizing world's agricultural efficiency depends largely on controlling pests and diseases. Although, demand for insecticides and fungicides by successful breeding for resistant cultivars has reduced, use of herbicides is still increasing globally. Application of heavy doses of herbicides is directly/indirectly causing negative impact on quality of produce, human health and environment. Allelopathic weeds and their allelochemicals have wide application prospects in increasing crop production, plant protection and biological control. This study was aimed at evaluating allelopathic activity of methanol extracts of Rhazya stricta (Harmal), Pinus roxburghii (Chir-Pine), Carica papaya (Papaw) and Lantana camara (Wild-sage) against selected weeds viz. Phalaris minor (Canary grass), Avena fatua (Wild oat), Chenopodium album (Goosefoot), Euphorbia helioscopia (Sun-spurge) and Rumex dentatus (Knotweed) on filter paper, soil and agar at 100\%, 75\%, 50\% and 0\% concentration. Germination percentage $(\%)$, radicle length $(\mathrm{cm})$ and plumule length $(\mathrm{cm})$ were parameters to assess allelopathic potential. The STATISTIX 9 software was used to analyse data. Based on results, it was concluded that methanolic extract of $R$. stricta, $P$. roxburghii, $C$. papaya and $L$. camara possess potential inhibitory effects amongst which $L$. camara showed most prominent inhibitory effects towards selected weeds. The germination and growth inhibition effects were found in order L. camara $>P$. roxburghii $>C$. papaya $>$ R. stricta. Detailed field study is recommended to establish allelopathic potential of these species to be utilized as phytoherbicide.
\end{abstract}

Keywords: third generation herbicides, ecofriendly weed management, bioassay screening, polar phytochemicals, seedling growth inhibition 


\section{Introduction}

Agriculture is the backbone of Pakistan's economy. This sector gave $20.9 \%$ of the Gross Domestic Product (GDP) for the fiscal year 2014-15. Moreover, agriculture is a source of income for $43.5 \%$ of the village population of the country. Food security depends upon a sustainable agricultural production and higher levels of yield. It may also enable the agricultural sector less vulnerable to the threat of climate change (Shah et al., 2016).

Wheat (Triticum aestivum L.), is one of the most important cereal crops of the world. Its role is quite important in the provision of human nutrition. It has been shown that wheat farmers are offering very little time and attention to the weed management practices, consequently, 15 to $25 \%$ wheat grain losses occur. Weeds are causing annual damage of about $10 \%$ in agricultural yields globally (Cavero et al., 2011). In Pakistan, weeds cause $45 \%$ loss in wheat production (Anwar et al., 2016).

In Pakistan, however, annual economic loss, due to weeds in agricultural production is estimated around 18.2 billion dollars. Including, 3-6 billion dollars spent on weeds control methods. There are around 30 different weed species generally found in the wheat crop, becoming the sources of losses. As the smaller farmers lack related tact and necessary resources, it becomes quite impossible to remove these weeds from the cultivated field. Weed harms most of the crops and grain. Moreover, it remains as a perennial problem in Pakistan's agriculture sector (Mubarik et al., 2015). Weeds are growing with cultivated crops and compete with crop for light, moisture, other vital elements of nutrition and space. The referred result cause low quality and less production of crops with raised costs of production. According to an estimate, grain produce in Pakistan can be enhanced by up to $41 \%$ if weeds are managed properly. The controlling of weeds through traditional methods is time consuming, weather hinged and exhibit more labour cost. While modern weed control techniques have not been up to the mark in solving this problem (Arafat et al., 2015).

Synthetic chemicals are in wider use for controlling weeds. These chemicals may enhance crop production, but concurrently these may have a negative effect on the environment as well as upon human health. In addition to these, the heading up of synthetic herbicides resistant weeds is another major area of concern. Excessive use of herbicides for controlling weeds during the last few years is becoming one of the noteworthy ecological and environmental threats for the world. Herbicide remnants in crops, soil and underground water, which cause an evolution of various resistant weed biotypes and linked health threats, are some of the huge dangers that scientists are facing these days in devising various weed management techniques. Due to the negative effect of using synthetic chemicals, one may highly be in demand the new classes of chemicals, especially, biodegradable products such as those originating from plants, which have the potential of being developed as herbicides (Aryakia et al., 2015). This guides us forward for searching new weed management strategies, which may be cost effective, easy and eco-friendly.

Allelopathy is a natural and eco-friendly technique. This strategy might be one of the very efficient tools for weed management and thereby increasing crop production (Kamran et al., 2017). An Austrian Professor Hans Molisch first used the term allelopathy in 1937. He got it from two Greek roots: allelon (of each other) and pathos (to suffer). It can be translated as the harmful effect of one organism upon any other. In the beginning, allelopathy referred to both killing and favorable interactions between 
any species. However, lately allelopathy is being used for only harmful plant interactions, rather for the both.

In 1996, the International Allelopathy Society defined allelopathy in the following words "The science that studies any process involving secondary metabolites produced by plants, micro-organisms, viruses, and fungi that influence growth and development of agricultural and biological systems" (Kong et al., 2006). Natural herbicides obtained from allelopathic plants can help in reducing usage of synthetic herbicides for weed control that will cause less pollution as well as alleviate human health concerns. The most commonly available allelochemicals are cinnamic and benzoic acids, alkaloids, flavonoids, phenolics, glucosionates and various terpenes (Khan et al., 2014).

Keeping all this in view, the present study was performed for evaluating Rhazya stricta (Harmal), Lantana camara (Wild-sage), Carica papaya (Papaw) and Pinus roxburghii (Chir-Pine), for their allelopathic activity against major weeds viz. Phalaris minor (Canary grass), Avena fatua (Wild oat), Chenopodium album (Goosefoot), Euphorbia helioscopia (Sun-spurge) and Rumex dentatus (Knotweed) of wheat (Triticum aestivum).

\section{Materials and methods}

Allelopathic potential of leaves of selected plants viz., $R$. stricta, $P$. roxburgii, $C$. papaya and $L$. camara was evaluated. Fresh leaves $(\sim 50 \mathrm{~g})$ for each species were

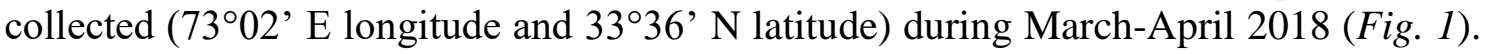
Collected plant material was washed under running tap water and dried at $30^{\circ} \mathrm{C}$ in laboratory that was crushed using heavy duty blender to make fine powder (mesh size $2 \mathrm{~mm}$ ) and preserved in air tight plastic zip lock bags (Ramsumair et al., 2014; Anwar et al., 2016). Seeds of test weeds viz. Phalaris minor, Avena fatua, Chenopodium album, Euphorbia helioscopia and Rumex dentatus were procured from the Barani Agricultural Research Institute (BARI), Pakistan. Seeds were surface sterilized by $2 \%$ solution of Sodium hypochlorite ( $\mathrm{NaOCl}$ ) (Biljana and Kragujevac, 2015).

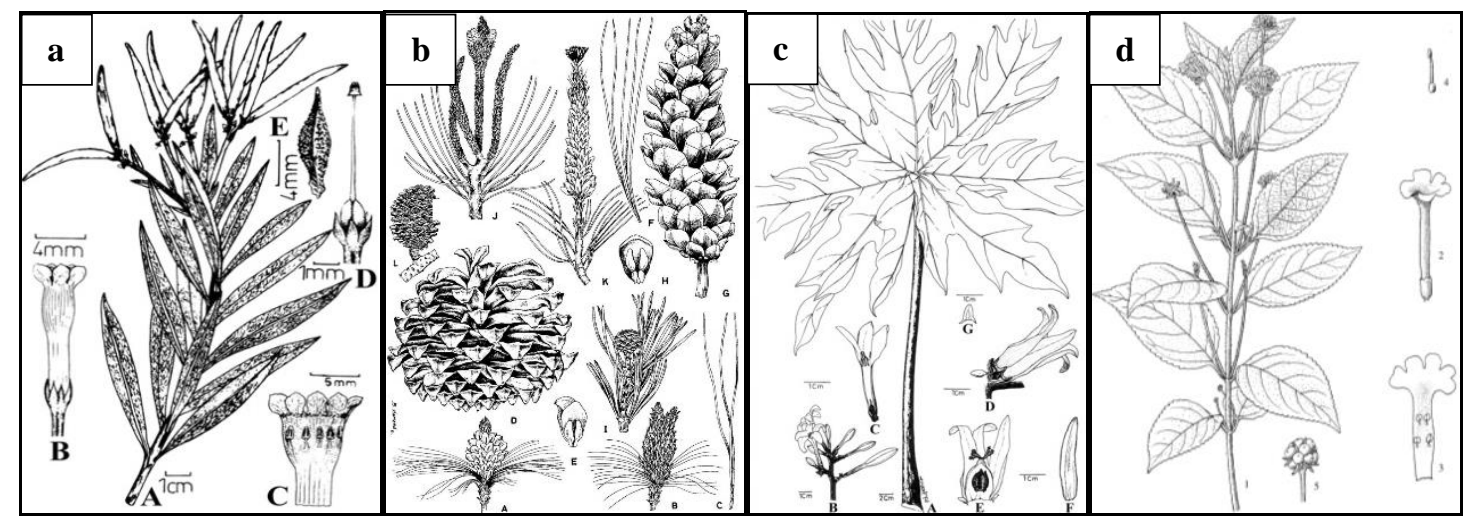

Figure 1. Illustrations of plants studied for their phytotoxic activity (a) Rhazya stricta, (b) Pinus roxburghii, (c) Carica papaya (d): Lantana camara (Pakistan eflora; http://www.efloras.org/flora)

Dried leaf powder of each plant species (40 g) was soaked in $400 \mathrm{ml}$ methanol and agitated for $24 \mathrm{~h}\left(25^{\circ} \mathrm{C}\right)$ at $160 \mathrm{rpm}$ on orbital shaker. The filtrate was obtained through 
Whatman filter paper No. 1. The final volume of filtrate was adjusted to $400 \mathrm{ml}$ that gave $10 \%$ methanol extract as stock solution. Three concentrations i.e. T1 (100\%), T2 (75\%), T3 (50\%) while T4 (0\%) were further prepared.

Bioassays were carried out using soil and filter paper as medium. An aliquot (15 ml) of extract for each of three concentrations was added on $25 \mathrm{~g}$ soil per petri dish while $5 \mathrm{ml}$ extract on filter paper per petri dish. Ten seeds of weed test species were used per petri dish. Each treatment was replicated three times. The petri dishes were wrapped with aluminium foil and incubated in growth chamber (NTS Model MI-25S set at $28^{\circ} \mathrm{C}$ ) for 15 days.

The germination percentage $(\%)$, lengths of radicle and plumule $(\mathrm{cm})$ were calculated by comparing with control (Maharjan et al., 2007; Anwar et al., 2017). The statistical analysis was carried out using STATISTIX 9 and means were separated by Fisher's protected LSD test (Nekonam et al., 2014).

\section{Results and discussion}

\section{Allelopathic potential of $R$. stricta}

The results obtained in indicated that $R$. stricta methanolic extract significantly inhibited germination of $C$. album (42\%) followed by $P$. minor $(41 \%)$ and $R$. dentatus (37\%) on filter paper, whereas, no significant effect on germination of $A$. fatua and $E$. helioscopia showing resistance against extract. Similarly, $R$. stricta methanolic extract on soil significantly suppressed seed germination of $C$. album (47\%) followed by $P$. minor (43\%) and $R$. dentatus (42\%). Maximum (95\%) germination was observed for $A$. fatua and E. helioscopia. It was recognized that minimum germination was noted for $C$. album i.e. $68 \%$ and $53 \%$ on filter paper and soil, respectively. The results revealed that germination reduction for $C$. album, $P$. minor and $R$. dentatus was concentration dependent (Fig. 2a).

The statistical data revealed that $R$. stricta methanolic extract significantly inhibited radical length of $R$. dentatus (45\%) and A. fatua (44\%) on filter paper, whereas, no significant effect was noted for $P$. minor, E. helioscopia and $C$. album showing resistance against extract. Similarly, the applications of extract into soil significantly suppressed radical length of $R$. dentatus (51\%) and A. fatua (50\%) as compared to control. The maximum (96\%) radical length was observed for P. minor, E. helioscopia and $C$. album. The final data concluded that minimum radical length was noted for $R$. dentatus i.e. $55 \%$ and $49 \%$ on filter paper and soil, respectively (Fig. $2 b$ ).

Analysis of the data revealed that $R$. stricta methanolic extract significantly suppressed the plumule length of A. fatua (33\%) and $R$. dentatus (28\%) as compared control on filter paper. Interestingly, there was no significant effect on plumule elongation of $P$. minor, E. helioscopia and $C$. album. Likewise, $R$. stricta methanolic extract significantly inhibited plumule length of $A$. fatua (55\%) and R. dentatus (34\%) in soil. The statistical figures also proposed that maximum plumule length $(96 \%)$ was noted for P. minor, E. helioscopia and C. album (Fig. 2c).

The plumule, radicle length and germination of cowpea and rice were significantly reduced with increasing concentration of $R$. stricta leaf extract (Jadhar and Gayanar, 1992). Moreover, inhibitory potential of different plants had pointedly checked seedling growth and seed germination of different crops and weed (Lisanework and Michelson, 1993; Khan et al., 2004) and their results exposed that extract of $R$. stricta inhibited plumule length of weed species. Similar results were also explained by Tefera, 2002 and 
Siddiqui et al., 2009. They noticed a suppressive effect on plumule length and seed germination. These findings were in accordance to Kaul and Bansal (2002) who stated that $R$. stricta leaf extract reduced growth of weeds species. Likewise, Maciel et al. (2003) also observed the same findings. The differences in germination response of tested species were expected and agree with those of Patil (1994) who reported variations in germination response of various field crops in the presence of $R$. stricta leaf extract. Some current revisions demonstrate the allelopathic potential of Parthenium hysterophorus (Tawaha and Turk, 2003), Brassica nigra (Singh et al., 2003) and Raphanus raphanistrum (Batish et al., 2002). All these revisions designate the production of allelochemicals during the preparation of extract. Likewise, results had been noted by Norsworthy (2003) while studying the inhibitory potential of different plants. They noticed that the leaf extracts had been more allelopathic in nature. The current results agree with the earlier findings described by Bora et al. (1999) who noticed the suppressive potential of $R$. stricta extract.

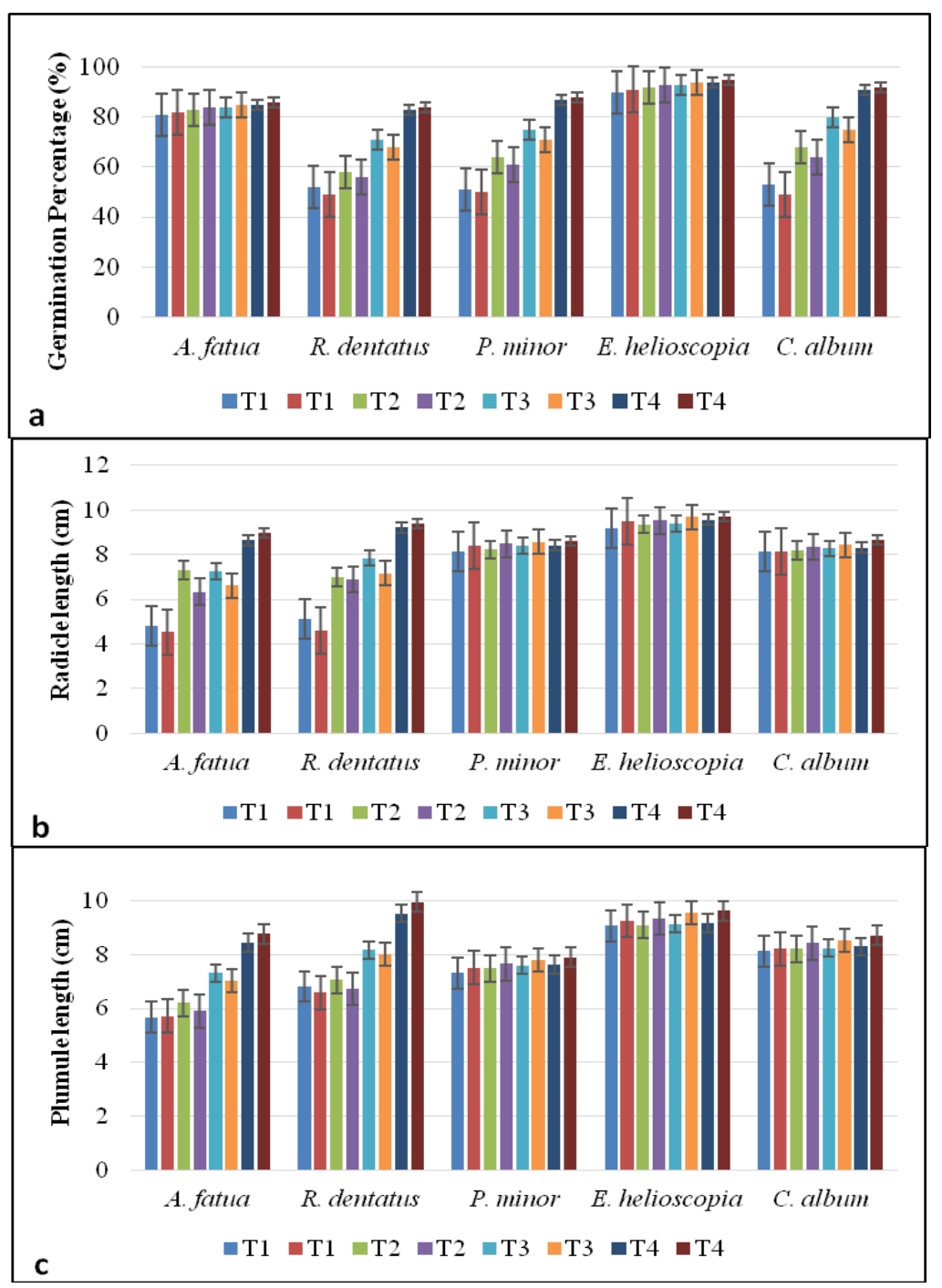

Figure 2. Allelopathic potential of R. stricta methanol extract on (a) germination (\%), (b) radicle length $(\mathrm{cm})$ and $(c)$ plumule length $(\mathrm{cm})$ against weed test species on filter paper $(F P)$ and soil (S) where; $T_{1}(100 \%), T_{2}(75 \%), T_{3}(50 \%)$ and $T_{4}$ (control) 


\section{Allelopathic potential of L. camara}

The statistical data exposed that $L$. camara methanolic extract significantly inhibited germination of $R$. dentatus (68\%), A. fatua (66\%), E. helioscopia (63\%) and P. minor $(62 \%)$ on filter paper, whereas, no significant effect on germination of $C$. album showing resistance against extract. Similarly, L. camara methanolic extract on soil significantly suppressed seed germination of A. fatua (76\%), E. helioscopia (73\%), $R$. dentatus $(70 \%)$ and $P$. minor (69\%). It was noted that maximum (95\%) germination was observed for $C$. album. In the present study, it was recognized that minimum germination percentage was noted for $R$. dentatus (32\%) followed by A. fatua (24\%) on filter paper and soil, respectively. The results revealed that germination reduction of the $R$. dentatus, A. fatua, E. helioscopia and $P$. minor were concentration dependent (Fig. 3a).

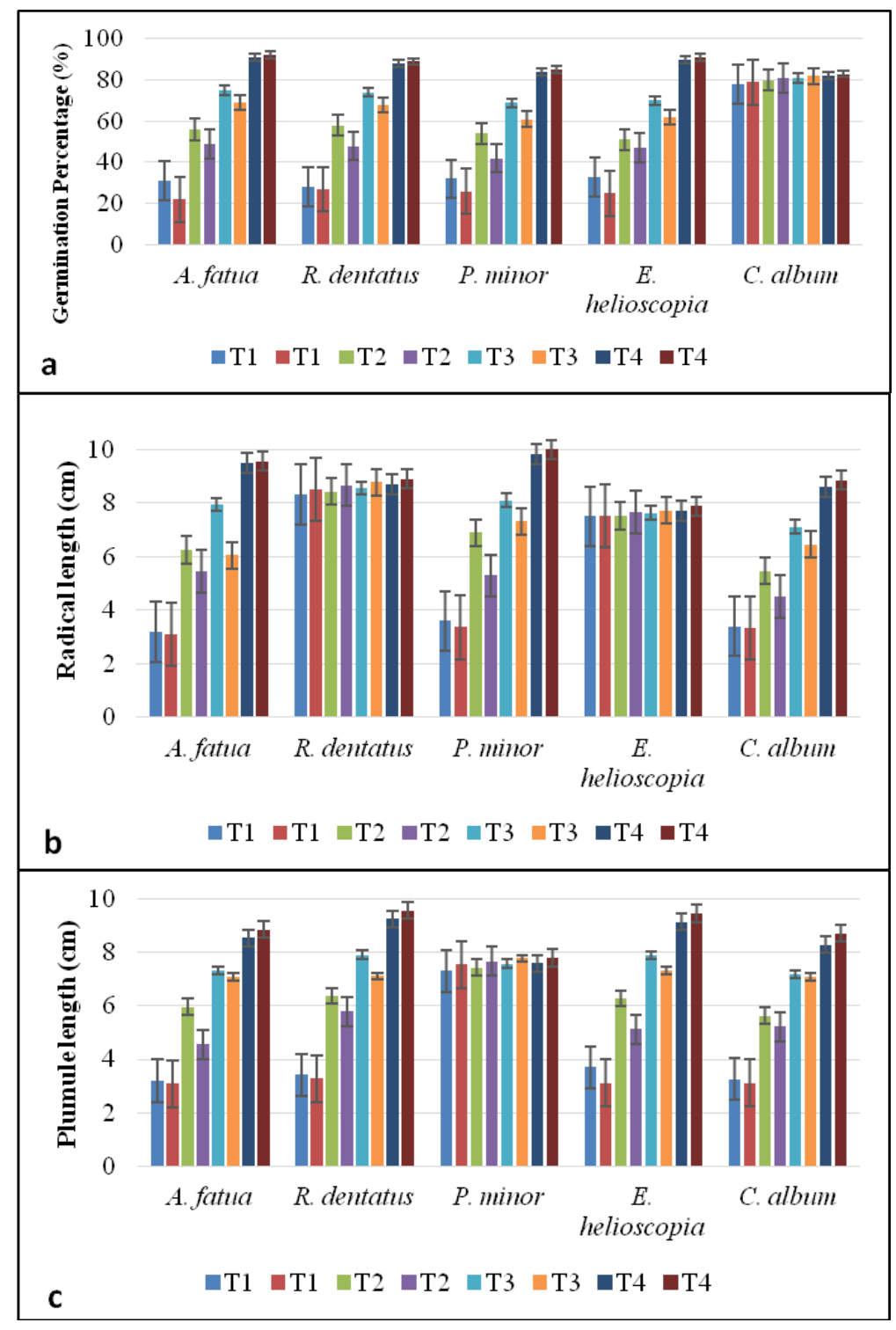

Figure 3. Allelopathic potential of L. camara methanol extract on (a) germination (\%), (b) radicle length $(\mathrm{cm})$ and $(\mathrm{c})$ plumule length $(\mathrm{cm})$ against weed test species on filter paper $(F P)$ and soil (S) where; $T_{1}(100 \%), T_{2}(75 \%), T_{3}(50 \%)$ and $T_{4}$ (control) 
The results obtained in the study indicated that $L$. camara methanolic extract significantly inhibited radical length of $C$. album (40\%), P. minor (37\%) and A. fatua (34\%) on filter paper, whereas, no significant effect was noted for $R$. dentatus and $E$. helioscopia showing resistance against extract. Similarly, the applications of extract into soil significantly suppressed radical length of A. fatua (68\%), P. minor (66\%) and $E$. helioscopia (63\%) as compared to control. The maximum (96\%) radical length was observed for $R$. dentatus and E. helioscopia. The final data concluded that minimum radical length was noted for C. album (60\%) and A. fatua (32\%) on filter paper and soil, respectively (Fig. 3b).

The data obtained exhibited that L. camara methanolic extract significantly suppressed the plumule length of $R$. dentatus (63\%), A. fatua (62\%), C. album (60\%) and E. helioscopia $(61 \%)$ as compared control on filter paper. Interestingly, there was no significant effect on plumule elongation of $P$. minor. Likewise, L. camara methanolic extract significantly inhibited plumule length of E. helioscopia (67\%), $R$. dentatus (66\%), A. fatua (65\%) and C. album (64\%) in soil. The statistical data concluded that minimum plumule length was noted for $R$. dentatus (37\%) and $E$. helioscopia (33\%) on filter paper and soil, respectively. The statistical figures also proposed that maximum plumule length (96\%) was noted for P. minor (Fig. 3c).

The results revealed that maximum germination was observed for $C$. album. The results further revealed that minimum germination was noted for $R$. dentatus and $A$. fatua showed being most susceptible to L. camara methanolic extract on filter paper and soil respectively. The data suggested that the maximum radical length was observed for $R$. dentatus and $E$. helioscopia showed most tolerance to allelopathic $L$. camara methanolic extract. The results indicated that minimum radical length was noticed for $A$. fatua. The study indicated that maximum plumule length was measured for $P$. minor. However, the lowermost plumule length was noticed for $R$. dentatus and E. helioscopia on filter paper and soil respectively. Mishra (2015) stated similar results that growth inhibitory effect of plants was concentration dependent. These results stated that $L$. camara has allelopathic effect on Lepidium sativum germination and growth. Ahmed et al. (2007) described the inhibitory potential of L. camara in different crops. Mishra (2012) stated that L. camara extract checked Parthenium hysterophorus seed germination demonstrating that the presence of inhibitory phytochemicals. Oudhia (2000) noticed germination of Melilotus alba was significant inhibited by extract of $L$. camara.

\section{Allelopathic potential of C. papaya}

The data illustrated that $C$. papaya methanolic extract significantly inhibited germination of $P$. minor (41\%), E. helioscopia (37\%) and A. fatua $(36 \%)$ on filter paper, whereas, no significant effect on germination of $R$. dentatus and $C$. album showing resistance against extract. Similarly, $C$. papaya methanolic extract on soil significantly suppressed seed germination of E. helioscopia (50\%), P. minor (45\%) and A. fatua (41\%). It was noted that maximum (95\%) germination percentage was observed for $R$. dentatus and $C$. album. In the present study, it was recognized that minimum germination was noted for P. minor (59\%) and E. helioscopia (50\%) on filter paper and soil, respectively. The results revealed that germination reduction of the $P$. minor, $E$. helioscopia and A. fatua were concentration dependent (Fig. 4a).

The data revealed that $C$. papaya methanolic extract significantly inhibited radical length of $P$. minor (47\%), $R$. dentatus (45\%) and A. fatua (42\%) on filter paper, 
whereas, no significant effect was noted for C. album and E. helioscopia showing resistance against extract. Similarly, the applications of extract into soil significantly suppressed radical length of $R$. dentatus (50\%), P. minor (49\%) and A. fatua (46\%) as compared to control. The maximum (96\%) radical length was observed for $C$. album and E. Helioscopia (Fig. 4b).

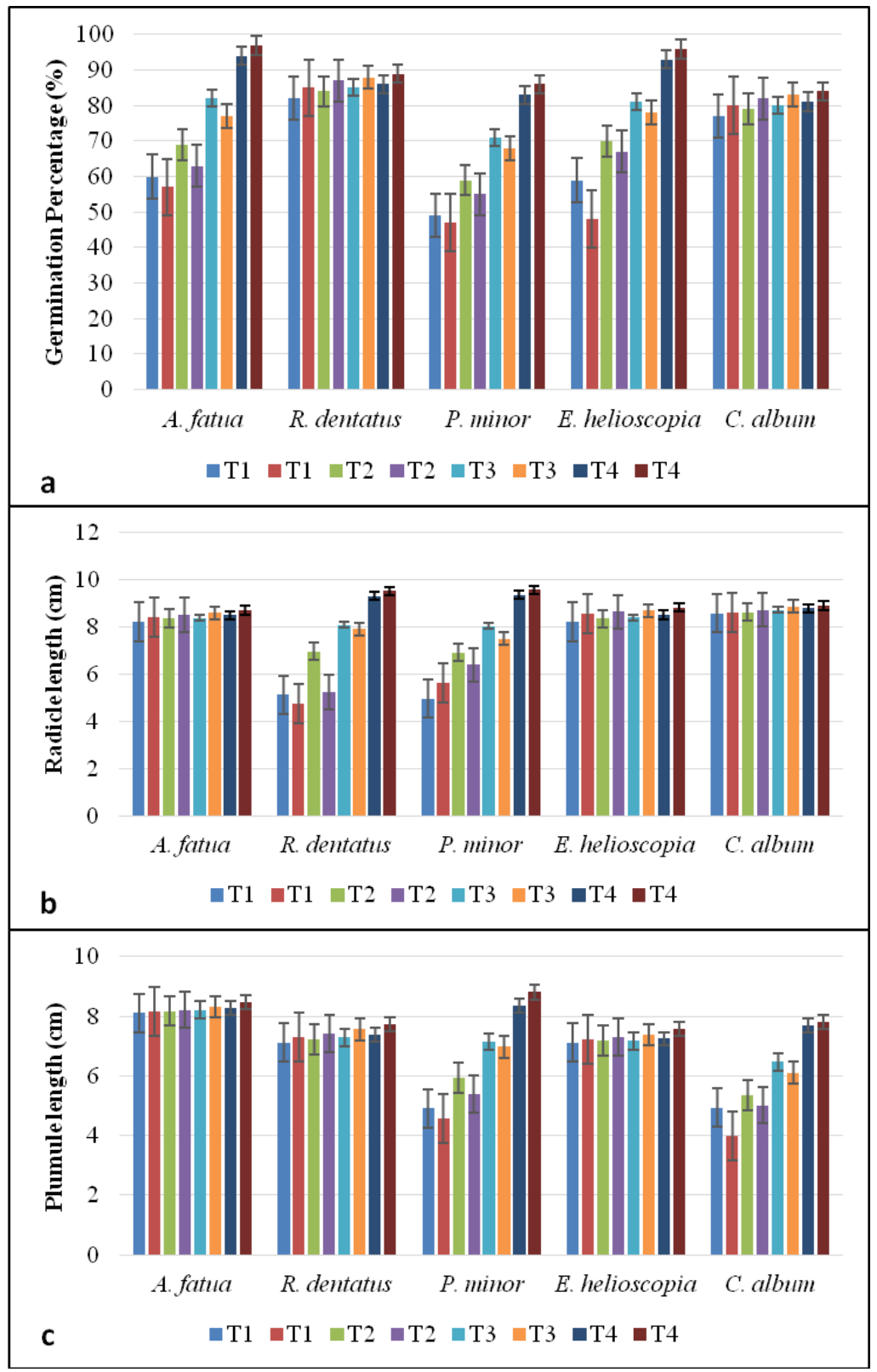

Figure 4. Allelopathic potential of C. papaya methanol extract on (a) germination (\%), (b) radicle length $(\mathrm{cm})$ and $(c)$ plumule length $(\mathrm{cm})$ against weed test species on filter paper $(F P)$ and soil (S) where; $T_{1}(100 \%), T_{2}(75 \%), T_{3}(50 \%)$ and $T_{4}$ (control)

The data obtained exhibited that $C$. papaya methanolic extract significantly suppressed the plumule length of $P$. minor $(41 \%)$ and $C$. album $(36 \%)$ as compared control on filter paper. Interestingly, there was no significant effect on plumule elongation of $A$. fatua, $R$. dentatus and E. helioscopia. Likewise, C. papaya methanolic 
extract significantly inhibited plumule length of C. album (49\%) and P. minor (48\%) in soil. The statistical data concluded that minimum plumule length was noted for $P$. minor (59\%) and C. album (51\%) on filter paper and soil, respectively. The statistical figures also proposed that maximum plumule length $(96 \%)$ was noted for A. fatua, $R$. dentatus and E. helioscopia (Fig. 4c).

The data also suggested that the maximum germination was observed for $R$. dentatus and $C$. album. The statistical results recommended that minimum germination percentage was noted for $P$. minor and E. helioscopia on filter paper and soil respectively. The highest radical length inhibition was measured for $C$. album and $E$. helioscopia. The statistical data concluded that maximum plumule length was measured for A. fatua, $R$. dentatus and E. helioscopia. The statistical results of the data showed that lowermost plumule length was noticed for $C$. album and $P$. minor on soil and filter paper respectively. Likewise, observations were also reported by Turk and Tawaha (2003) showing negative germination effects by $C$. papaya extract of on Avena fatua. According to observations of Bajwa et al. (2013) different types of plant extracts were observed to be completely inhibitory on germination of $A$. fatua. Likewise, finding was also reported by Oudhi (2001) and Maharjan et al. (2007).

\section{Allelopathic potential of $P$. roxburghii}

P. roxburghii methanolic extract on filter paper showed significant inhibitory activity on seed germination of C. album (49\%) and A. fatua (46\%), respectively as compared to control. Likewise, P. roxburghii methanolic extract on soil exhibited the highest degree of inhibition germination for C. album (52\%) and A. fatua (49\%) respectively as compared to control. The statistical data also suggested that the there was no significant effect on germination percentage of $P$. minor, $R$. dentatus and E. helioscopia. The maximum (98\%) germination was observed for $P$. minor, $R$. dentatus and $E$. helioscopia. The statistics recommended that allelopathic inhibitory effect was concentration dependent for C. album and A. fatua (Fig. 5a).

The data revealed that the highest radical length inhibition activity exhibited by $R$. dentatus $(47 \%)$ followed by $C$. album $(43 \%)$ in P. roxburghii methanolic extract on filter paper. Likewise, methanolic extract on soil caused significant radical length reduction of $R$. dentatus and $C$. album measuring $50 \%$ and $48 \%$, respectively as compared to control, while $P$. minor, E. helioscopia and A. fatua remained unaffected. The maximum radical length was noted for P. minor, E. helioscopia and A. fatua (98\%). The results also illustrated that minimum radical length was noted for $R$. dentatus i.e. $53 \%$ and $50 \%$ on filter paper and soil, respectively. The results revealed that allelopathic inhibitory effect was concentration dependent for $R$. dentatus and C. album (Fig. 5b).

$P$. roxburghii methanolic extract on filter paper significantly inhibited plumule length of $R$. dentatus (46\%) and A. fatua (42\%). Likewise, the highest degree of inhibition in plumule length was measured for R. dentatus (49\%) and A. fatua (45\%) in methanolic extract applied into soil. The data further suggested that there was no significant effect on germination of $P$. minor, E. helioscopia and $C$. album. The statistical results recommended that highest plumule length $(98 \%)$ was exhibited by $P$. minor, E. helioscopia and C. album. The results further indicated that minimum plumule length noticed for $R$. dentatus i.e. $54 \%$ and $51 \%$ on filter paper and soil, respectively. The statistics also recommended that allelopathic inhibitory effect was concentration dependent for $R$. dentatus and A. fatua (Fig. 5c). 


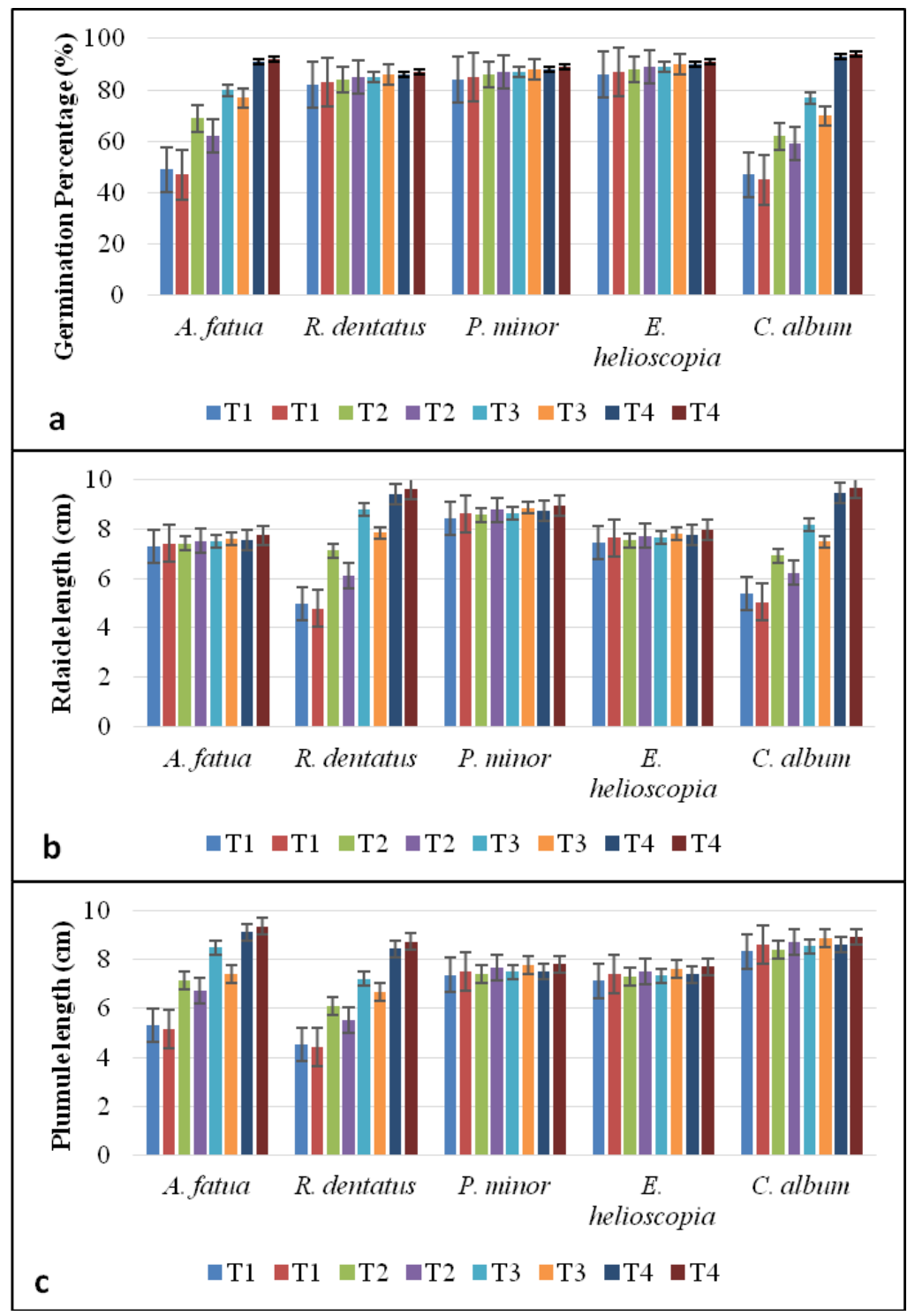

Figure 5. Allelopathic potential of P. roxburghii methanol extract on (a) germination (\%), (b) radicle length $(\mathrm{cm})$ and $(c)$ plumule length $(\mathrm{cm})$ against weed test species on filter paper $(F P)$ and soil (S) where; $T_{1}(100 \%), T_{2}(75 \%), T_{3}(50 \%)$ and $T_{4}$ (control)

It was revealed that maximum germination was observed for $P$. minor, $R$. dentatus and E. helioscopia. The results recommended that the maximum radical length was noted for P. minor, E. helioscopia and A. fatua. The results illustrated that minimum radical length was noted for $R$. dentatus. It was observed that $P$. minor, E. helioscopia and $C$. album exhibited highest activity for plumule length. The results further indicated that minimum plumule length noticed for $R$. dentatus. The black pine was shown to inhibit the growth of Phalaris canariensis, Trifolium campestre and Sinapis arvensis seeds (Amri et al., 2013). Different pinene isomers exhibited allelopathic potential against Zea mays seed germination (Areco et al., 2014). The leaf methanolic extract from $P$. nigra suppressed the seed germination of perennial ryegrass and tall fescue (Robert, 1986; Terzi et al., 2013). Valera-Burgos et al. (2012) noticed inhibitory 
potential of Pinus pinea needles extract on seedling growth and seed germination of three Mediterranean shrub species.

Some recent studies indicating the phytotoxic/allelopathic effect of weeds include Raphanus raphanistrum (Ali, 2016), Brassica napus (Rodriguez et al., 2016), Ageratum conyzoides (Kumar et al., 2018) and Parthenium hysterophorus (Saranya et al., 2019). All these studies indicate the release of phototoxic chemicals. Based on this, studies were further extended to explore the impact of selected species, as they possessed greater phytotoxicity on the emergence and growth of weed plants in wheat crop.

\section{Conclusions}

Experiments showed that methanolic extracts of selected plants at higher concentrations reduce the seed germination, radicle and plumule length of weeds associated with the wheat crop. Results provided evidence about herbicidal potential of tested plant species viz. L. camara, P. roxburghhii, $C$. Papaya and $R$. stricta against weeds of wheat crop (Avena fatua, Phalaris minor, Chenopodium album and Rumex dentatus). Further work is recommended to appraise the potential inhibitory effects of allelochemicals from these plants.

\section{REFERENCES}

[1] Ali, K. A. (2016): Allelopathic potential of radish (Raphanus sativus L.) on germination and growth of some crop and weed plants. - Int. J. Biosci. 9: 394-403.

[2] Ahmed, R., Uddin, M. B., Khan, M. A., Mukul, S. A., Hossain, M. K. (2007): Allelopathic effects of Lantana camara on germination and growth behavior of some agricultural crops in Bangladesh. - J. For. Res. 18: 301-304.

[3] Amri, I., Hamrouni, L., Hanana, M., Gargouri, S., Fezzani, T., Jamoussi, B. (2013): Chemical composition, physico-chemical properties, antifungal and herbicidal activities of Pinus halepensis Miller essential oils. - Biol. Agric. Hortic. 29: 91-106.

[4] Anwar, T., Khalid, S., Saeed, M., Mazhar, R., Qureshi, H., Rashid, M. (2016): Allelopathic interference of leaf powder and aqueous extracts of hostile weed: Parthenium hysterophorus (Asteraceae). - Sci. Int. 4: 86-93.

[5] Anwar, T., Khalid, S., Panni, M. K., Qureshi, H., Rashid, M. (2017): Allelopathic effect of Euphorbia helioscopia on Avena fatua, Rumex dentatus, Helianthus annuus, Zea mays and Triticum aestivum. - Pak. J. Weed Sci. Res. 23: 165-177.

[6] Arafat, Y., Khalid, S., Lin, W., Fang, C., Sadia, S., Ali, N., Azeem, S. J. (2015): Allelopathic evaluation of selected plants extract against broad and narrow leaves weeds and their associated crops. - Acad. J. Agric. Res. 3: 226-234.

[7] Areco, V. A., Figueroa, S., Cosa, M. T., Dambolena, J. S., Zygadlo, J. A., Zunino, M. P. (2014): Effect of pinene isomers on germination and growth of maize. - Biochem. Syst. Ecol. 55: 27-33.

[8] Aryakia, E., Naghavi, M. R., Farahmand, Z., Fazeli, S. A. H. S. (2015): Evaluating allelopathic effects of some plant species in tissue culture media as an accurate method for selection of tolerant plant and screening of bioherbicides. - J. Agr. Sci. Tech. 17: 1011-1023.

[9] Bajwa, A. H., Khalid, S., Sadia, S., Nabeel, M., Nafees, W. (2013): Influence of combinations of allelopathic water extracts of different plants on wheat and wild oat. Pak. J. Weed Sci. Res. 19: 157-166. 
[10] Batish, D. R., Singh, H. P., Kohli, R. K., Saxena, D. B., Kaur, S. (2002): Allelopathic effect of parthenium against two weedy species, Avena fatua and Bidens pilosa. Environ. Exp. Bot. 47: 149-155.

[11] Biljana, M. B., Kragujevac, D. Z. J. (2015): Allelopathic relations of selected cereal and vegetable species during seed germination and seedling growth. - J. Sci. 37: 135-142.

[12] Bora, I. P., Singh, J., Borthakur, R., Bora, E. (1999): Allelopathic effect of leaf extracts of Acacia auriculiformis on seed germination of some agricultural crops. - Annl. For. 7: 143-146.

[13] Cavero, J., Zaragoza, C., Cirujeda, A., Anzalone, A., Faci, J. M., Blanco, O. (2011): Selectivity and weed control efficacy of some herbicides applied to sprinkler irrigated rice (Oryza sativa L.). - Spanish J. Agric. Res. 9: 597-605.

[14] Jadhar, B. B., Gayanar, D. G. (1992): Allelopathic effects of Acacia auriculiformis on germination of rice and cowpea. - Ind. J. Plant Physiol. 1: 86-89.

[15] Kamran, M., Raza, A., Ali, Q., Ali, H. H., Chattha, M. S. (2017): Investigating the influence of fertilizer and allelopathic water extracts on maize and associated weeds. Pak. J. Weed Sci. Res. 23: 361-378.

[16] Kaul, S., Bansal, G. L. (2002): Allelopathic effect of Ageratina adenophoraon growth and development of Lantana camara. - Ind. J. Plant Physiol. 7: 195-197.

[17] Khan, I., Ali, Z., Khan, M. I., Hussain, Z., Khan, I. A., Waqas, M., Khan, R., Khan, S. (2014): Allelopathic effects of some weeds on chickpea crop. - Pak. J. Weed Sci. Res. 20: 207-211.

[18] Khan, M. A., Marwat, K. B., Hassan, G., (2004): Allelopathic potential of some multipurpose trees species (MPTS) on the wheat and some of its associated weeds. - Int. J. Biol. Biotechnol. 1: 275-278.

[19] Kong, C. H., Li, H. B., Hu, F., Xu, X. H., Wang, P. (2006): Allelochemicals released by rice roots and residues in soil. - Plant Soil 288: 47-56.

[20] Lisanework, N., Michelen, A. (1993): Allelopathy in agro forestry systems. The effects of leaf extracts of eucalyptus species on three crops. - Agro-Forestry Syst. 21: 63-74.

[21] Maciel, C. D. G., Correa, M. R., Alves, E., Negrisoli, E., Velini, E. D., Rodrigues, J. D., Ono, E. O., Boaro, C. S. F. (2003): Influence of Brachiaria decumbens straw management on the initial development of soybean (Glycine max) and peanut-brav (Euphorbia heterophylla). - Plant Weed 21(3): 635-637.

[22] Maharjan, S., Shrestha, B. B., Jha, P. K. (2007): Allelopathic effects of aqueous extract of Parthenium hysterophorus L. on seed germination and seedling growth of some cultivated and wild herbaceous species. - Sci. World 5: 35-39.

[23] Mishra, A. (2012): Allelopathic interaction of Lantana camara leaf of extract on growth of Parthenium hysterophorus in seedling stage. - Int. J. Plant Sci. 7: 259-262.

[24] Mishra, A. (2015): Review; Allelopathic properties of Lantana camara. - Int. Res. J. Basic Clin. Stud. 3: 13-28.

[25] Mubarik, S., Khan, K., Memon, R. A., Shaheen, G., Hashmatulla. (2015): Allelopathic effects of important weeds on germination and growth of maize (Zea mays L.). - Pak. J. Weed Sci. Res. 21: 181-180.

[26] Nekonam, M. S., Kraimmojeni, H., Sharifnabi, B., Razmjoo, J., Amini, H., Bahrami, F. (2014): Assessment of some medicinal plants for their allelopathic potential against redroot pigweed (Amaranthus retroflexus). - J. Plant Prot. Res. 54: 90-95.

[27] Norsworthy, J. K. (2003): Allelopathic potential of wild radish (Raphanus raphanistrum). - Weed Technol. 17: 307-313.

[28] Oudhi, P. A. (2001): Germination and seedling vigour of wheat as affected by allelopathy of some obnoxious weeds. - Agric. Sci. Digest. 21: 275-276.

[29] Oudhia, P. (2000): Allelopathic effects of some obnoxious weeds on germination of Melilotus alba. - Legume Res. 22: 133-134.

[30] Patil, B. P. (1994): Effects of Glyricidia maculate L. extracts on field crops. Allelopathy J. 1: 118-120. 
[31] Ramsumair, A., Mlambo, V., Lallo, C. H. O. (2014): Effect of drying method on the chemical composition of leaves from four tropical tree species. - Trop. Agric. (Trinidad) 91: 179-186.

[32] Robert, J. (1986): Allelopathic potential of coniferous species to old-field weeds in Eastern Quebec. - For. Sci. 32: 112-118.

[33] Rodriguez, D., Casagrande, G., Carmona-Galindo, V. D. (2016): Effects of black mustard allelopathy on the fitness and life history strategies of buffalo gourd in southern California. - Bios 87(3): 98-103.

[34] Saranya, M., Rangaraj, T., Ragavan, T., Amutha, R. (2019): Allelopathic Potential of Parthenium hysterophorus and Tridax procumbens aqueous leaf extracts on weed control and growth of Blackgram (Vigna mungo L.). - Int. J. Agric. Sci. 11: 7697-7700.

[35] Shah, S. H., Khan, E. A., Shah, H., Ahmed, N., Khan, J., Sadozai, G. U. (2016): Allelopathic sorghum water extract helps to improve yield of sunflower (Helianthus annuus L.) - Pak. J. Bot. 48: 1197-1202.

[36] Siddiqui, S., Meghvansi, M. K., Yadav, K., Yadav, R., Wani, F. A., Ahmad, A. (2009): Efficacy of aqueous extracts of five arable trees on the seed germination of Pisum sativum L. var. VRP-6 and KPM-522. - Botany Res. Int. 2: 30-35.

[37] Singh, H. P., Batish, D. R., Pandher, J. K., Kohli, R. K. (2003): Assessment of allelopathic properties of Parthenium hysterophorus residues. - Agric. Ecosyst. Environ. 95: 537-541.

[38] Tawaha, A. M., Turk, M. A. (2003): Allelopathic effects of black mustard (Brassica nigra) on germination and growth of wild barley (Hordeum sponataneum). - J. Agron. Crop Sci. 189: 298-303.

[39] Tefera, T. (2002): Allelopathic effects of Parthenium hysterophorus extracts on seed germination and seedling growth of Eragrostis tef (Zucc.) Trotter. - J. Agron. Crop Sci. 188: 306-310.

[40] Terzi, I., Kocacaliskan, I., Demir, Y. (2013): Allelopathic effects of some tree leaf extracts on seed germination and seedling growth of turf grasses. - J. Environ. Prot. Ecol. 14: 1236-1243.

[41] Turk, M. A., Tawaha, A. M. (2003): Allelopathic Effect of Black Mustard (Brassica nigra L.) on the germination and growth of wild oat (Avena fatua L.). - Crop Prot. 22: 673-677.

[42] Valera-Burgos, J., Diaz-Barradas, M. C., Zunzunegui, M. (2012): Effects of Pinus pinea Litter on seed germination and seedling performance of three Mediterranean shrub species. - Plant Growth Regul. 66: 285-292. 